\title{
The Computerized Self Test (CST): An Interactive, Internet Accessible Cognitive Screening Test For Dementia
}

\author{
John H. Dougherty Jr. ${ }^{a}$, Rex L. Cannon ${ }^{\mathrm{a}, \mathrm{b}, *}$, Christopher R. Nicholas ${ }^{\mathrm{a}, \mathrm{c}}$, Lorin Hall ${ }^{\mathrm{a}}$, Felicia Hare ${ }^{\mathrm{a}}$, \\ Erika Carr ${ }^{\mathrm{a}, \mathrm{d}}$, Andrew Dougherty ${ }^{\mathrm{e}}$, Jennifer Janowitz ${ }^{\mathrm{a}}$ and Justin Arunthamakun ${ }^{\mathrm{a}, \mathrm{f}}$ \\ ${ }^{a}$ Cole Neuroscience Center, Memory Disorder Clinic, University of Tennessee Medical Center, Knoxville, TN, USA \\ ${ }^{\mathrm{b}}$ Biological Psychology and Neuroscience Laboratory, Department of Psychology, University of Tennessee, \\ Knoxville, TN, USA \\ ${ }^{\mathrm{c}}$ Clinical Psychology Program, Department of Psychology, University of Tennessee, Knoxville, TN, USA \\ ${ }^{\mathrm{d}}$ Counseling Psychology Program, Department of Psychology, University of Tennessee, Knoxville, TN, USA \\ ' Medical Interactive Education, LLC, Knoxville, TN, USA \\ ${ }^{\mathrm{f}}$ Neuroscience, Financial Economics, Biology, Vanderbilt University, Nashville, TN, USA
}

Accepted 8 December 2009

\begin{abstract}
The computer self test (CST) is an interactive, internet-based instrument designed to assess functional cognitive domains impaired by Alzheimer's disease (AD) and mild cognitive impairment (MCI). This study consisted of 215 total subjects with a mean age of 75.24. The 84 cognitively impaired patients (excluding patients diagnosed as MCI) met all criteria set forth by NINCDS/ADRDA for the diagnosis of AD. Control participants consisted of 104 age-matched individuals who were cognitively unimpaired. All patients completed the CST prior to other routine neurocognitive procedures. The CST accurately classified $96 \%$ of the cognitively impaired individuals as compared to controls, while the Mini-Mental Status Examination (MMSE) accurately classified $71 \%$ and the Mini-Cog $69 \%$ in the same respect. In addition, the CST accurately classified $91 \%$ of the six experimental groups (control, MCI, early AD, mild to moderate, moderate to severe, and severe) as compared to 54\% for the MMSE and $48 \%$ for the Mini-Cog. In conclusions, the CST demonstrates a high degree of sensitivity and specificity and is capable of accurately identifying cognitive impairment in patients with variable degrees of cognitive abnormality. This interactive internet-based cognitive screening tool may aid in early detection of cognitive impairment in the primary care setting. The ease of use and interpretation may also provide the means to obtain an accurate baseline from which to monitor cognitive changes over time.
\end{abstract}

Keywords: Alzheimer's disease, computerized cognitive screening, dementia, mild cognitive impairment

\section{INTRODUCTION}

In its earliest stages, Alzheimer's disease (AD) may include cognitive impairments in any single or multi-

*Correspondence to: Rex Cannon, Cole Neuroscience Center, University of Tennessee Medical Center, 1928 Alcoa Highway, Medical Building B, Suite 102, Knoxville, TN 37920, USA. Tel.: +1 865 300 4983; E-mail: rcannon2@utk.edu. ple cognitive domains, including: memory, verbal fluency, orientation, visuospatial organization, executive functions, attention, and cognitive processing speed. Deficits in awareness (anosognosia) and spontaneity (affect) are also observed [1,2]. Given the insidious onset of these symptoms, early detection in the primary care setting would be an important venue to facilitate available medications that have been shown to more effectively slow the progression of AD when adminis- 
tered in its early stages [3-5].

Current data suggest that $60 \%$ of the patients with $\mathrm{AD}$ are not diagnosed in the primary care setting [6]. To date, there is debate over the most practical way to assess early symptoms in AD [7-9]. Research continues to stress the importance of delineating mild cognitive impairment (MCI) from the prodrome of AD [9-12], while others propose that MCI might be better classified as a pre-dementia (pre-AD) condition [13-15]. In order for brief screening instruments to be effectively adapted to the primary care setting, they must be easy to interpret, accurate, and administered with only minimal supervision. In the last decade it has become clear that memory screening alone is not adequate for the early diagnosis of AD [16,17]. Differentiation of other forms of dementia with distinct neurocognitive patterns (Diffuse Lewy Body Disease, Subcortical Vascular Dementia, Frontal Lobe Dementia) from AD within patients presenting with memory complaints is of particular interest to researchers [18] as well as clinicians [19,20]. Brief screening instruments have been developed with acceptable levels of sensitivity and specificity [21-26]. However, prior studies suggest that improvements in the practical application and interpretation of these instruments will aid in their usefulness in both specialty clinics and primary care setting [7]. Brief screening instruments that provide research supported construct validity in assessing specific cognitive domains at risk are needed, specifically: orientation $[27,28]$, visuospatial and executive processing [29-31], verbal fluency [32, 33], working memory [34-37], and attention and processing speed $[38,39]$.

The Computerized Self Test (CST) was adapted from a paper and pencil Self Test used in the memory disorders clinic [24], which assesses all six cognitive domains as well as processing speed. The CST was designed with three important issues in mind for establishing a new cognitive screening test. First, the instrument must be constructed in such a way that the patient alone or with the assistance of a family member and/or caregiver (to assist with the computer interface only) could complete the test with minimal supervision. Second, the instrument must incorporate research findings that demonstrate that the clock drawing and verbal fluency tests are sensitive measures of early cognitive changes in dementia and AD [40,41]. Finally, the instrument must be computer and internet based to allow for easy access, to minimize professional time for administration and to facilitate objective scoring.

The CST was created following indications that assessing multiple cognitive domains within the same prediction model will aid in identifying persons at risk for developing AD [42]. The CST assesses verbal fluency, visual-spatial functions, memory, attention, executive functions, and perceptual/processing speed in approximately 15 minutes. The CST is designed to detect early deficits in one or more specific cognitive domains with adherence to the guidelines that any screening test does not produce a definitive diagnosis of dementia [43] and comprehensive neuropsychological and clinical assessments are needed to make a probable or possible diagnosis [44].

We hypothesized that the combination of measures in the CST would provide an accurate prediction model for discriminating between six experimental groups (normal, MCI, early AD, mild to moderate $\mathrm{AD}$, moderate to severe $\mathrm{AD}$, and severe $\mathrm{AD}$ ) with special consideration given to the global deficits between cognitively impaired (CI) and control groups.

\section{MATERIALS AND METHODS}

\section{Participants}

This study consisted of 215 total participants with a mean age of 75.24. The 84 cognitively impaired patients (excluding patients diagnosed as MCI, $n=27$ ) met all criteria set forth by NINCDS/ADRDA for the diagnosis of AD. Exclusion criteria included: stroke (large vessel), psychiatric disorders, diagnosis of alcohol abuse or alcoholism, presence of prior neurological disease, and significant sensory deficits or physical impairment that would preclude interaction with the computer or caregiver. The CI group consisted of current patients seen and followed at our memory disorders clinic that have met all criteria and received a diagnosis of AD as set forth by the National Institute of Neurological and Communicative Disorders and Stroke and the Alzheimer's disease and Related Disorders Association. Patients with MCI met appropriate criteria as outlined by Petersen [45]. The control group consisted of spouses of affected individuals and from individuals recruited from volunteer organizations working within the medical center. All controls completed the same neurocognitive procedures as the CI group with the addition of the Montreal Cognitive Assessment (MoCA) $[46,47]$ to aid in the identification of individuals with possible mild cognitive impairments.

Table 1 shows the demographic information for each group; included in the table are the group, number in group $(\mathrm{N})$, mean age, range, standard deviation (SD), 
Table 1

Demographics for participants. From left to right are the diagnostic group, size, mean age, range, standard deviation, gender per group, years of education with range and standard deviation

\begin{tabular}{|c|c|c|c|c|c|c|c|c|}
\hline Group & Size $(N)$ & Mean age & Range & SD & Gender & Edu & range & $\mathrm{SD}$ \\
\hline Control & 104 & 75.45 & $58-89$ & 7.25 & $\begin{array}{l}\text { M } 41 \\
\text { F } 63\end{array}$ & 15 & $8-20$ & 2.70 \\
\hline MCI & 27 & 67.24 & $53-78$ & 6.42 & $\begin{array}{c}\text { M } 24 \\
\text { F } 3\end{array}$ & 14 & $8-20$ & 4.07 \\
\hline Early AD & 22 & 77.45 & $68-91$ & 5.22 & $\begin{array}{l}\text { M } 6 \\
\text { F } 16\end{array}$ & 14 & $8-20$ & 2.96 \\
\hline Mild to Moderate & 33 & 75.21 & $56-94$ & 9.08 & $\begin{array}{l}\text { M } 14 \\
\text { F } 19\end{array}$ & 14 & $12-20$ & 3.03 \\
\hline Moderate to Severe & 24 & 78.39 & $65-89$ & 6.60 & $\begin{array}{l}\text { M } 14 \\
\text { F } 10\end{array}$ & 13 & $12-20$ & 2.84 \\
\hline Severe & 5 & 75.00 & $71-80$ & 3.53 & $\begin{array}{l}\text { M } 1 \\
\text { F } 4\end{array}$ & 15 & $12-16$ & 1.79 \\
\hline
\end{tabular}

gender, and mean education in years, with range and standard deviation. The diagnosis of dementia and classification into the appropriate group (MCI, stages of dementia) were performed by an experienced Neurologist and Geriatric Psychiatrist. They had an opportunity to review the results of all cognitive data but were blinded to the results of the CST. In addition, all patients were examined and are followed either by the Neurologist or Geriatric Psychiatrist on a regular basis in the memory disorder clinic. The neurocognitive measures administered to all individuals in the memory disorders clinic are: MMSE, paper self test, Mini-Cog, test of executive functions, test of verbal fluency, MoCA (when indicated), Geriatric depression scale, caregiver/spouse/family member interview, and clinical examination. Diagnoses are based on a composite of these measures. The groups in this study were classified in a similar fashion with MMSE scores as a reference base. The MMSE scores for each group are: Control (28-30), MCI (26-29/MoCA $<26$ and $>20$ ), Early AD (23-26), mild to moderate AD (18$22)$, moderate to severe AD (11-18), and severe AD $(<10)$, respectively.

\section{Data collection and processing}

The CST was administered prior to routine neurocognitive measures given to patients in the memory disorders clinic. The patients and or caregivers were asked at the time of their appointment if they would like to participate in a research trial. All participants and or caregivers were read, signed, and agreed to the informed consent protocol approved by the Institutional Review Boards of the Volunteer Research Group and the University of Tennessee Medical Center. All participants were paid $\$ 10$ for participation. The testing procedures were carried out in a standardized fashion utilizing portable laptop computers with the patients, caregivers or both seated in examination rooms. The assessment instruments were administered in the order listed in the following section.

\section{Assessment measures}

(i) The CST is internet based and takes approximately 15 minutes to complete. It provides a user friendly interface with both written and oral instructions. If the participant reports experience with computers, he or she continues on with the test independently. If the participant reports no experience with computers and requires help to operate a computer, the caregiver is asked to administer the test. Alternatively, if asked, a technician is also available for assistance with test administration. The caregiver, family member, or technician may manipulate the mouse or arrows for the patient or facilitate the typing and entering of patient responses. These individuals, however, are given explicit instructions not to provide aid or hints to the patient in order to obtain the most accurate results. The CST was not used in the diagnostic criteria for any of the study participants. The CST was created with carefully manipulated assessment and scoring mechanisms that are unique to this instrument. In cognitive testing, there is often significant overlap between test content [48], in part due to the inherent nature of human cognition and its dependence on language. Thus, in content, scoring, and delivery, the CST is a novel and unique instrument. Painstaking attention was also applied to the results as seen by the patient, such that no inference 
or indication that may lead to the interpretation of a diagnosis of dementia is given to the patient.

\section{CST content}

The CST obtains demographic information on the initial screen. This information includes, gender, age, computer experience, self-report of memory problems, family history of memory problems or dementia and if assistance is needed to complete the CST. The CST assesses six cognitive domains.

\section{Visual spatial/executive processing}

The clock drawing test $[49,50]$ is presented on three screens. First the participant is presented a selection of four geometric shapes from which he or she is to choose the shape that best represents a clock face. Second, clock numbers $(12,3,6$, and 9) are presented in succession. The participant is asked to click on the clock face where each of the numbers should go. Finally, the participant is presented a selection of clock hands. Only one clock-hand set will produce the time at ten after eleven. The participant has to click on the correct choice and can score up to 4 points. This type of clock construction task reduces the demand on motoric functions [51] and reduces the likelihood of errors in scoring due to motor slowing produced in normal aging [52].

\section{Working memory}

Engle and colleagues [53] proposed that working memory [54-56] capacity is the ability to temporarily maintain representations with distraction or interference. The complex span task requires maintenance of a list of items to be recalled in the face of other information that needs to be processed but is irrelevant to the memory task. Hence, list elements must be maintained in working memory, but in addition, the task requires executive attention $[57,58]$ in order to preserve these representations during an interference or secondary task. The memory and attention subtests were developed with these fundamental concepts in mind. The participants are presented three words and given instructions to study the words and commit them to memory. The participants are then presented a screen with three blank text boxes after the verbal fluency section of the test and asked to type in the three words. The memory section algorithm automatically detects the correct word based on the first three letters and it is entered into the text field for the patient. There are 3 points possible for this section. The three words for the memory subtest are maintained algorithmically and randomly changed for each test administration to hinder possible test-retest learning effects.

\section{Verbal fluency}

Verbal fluency has been demonstrated to be an important component of semantic memory. The verbal fluency section of the CST asks participants to name 15 animals as quickly as possible. The database for verbal fluency operates through an algorithm of word-pattern matching (includes $\sim 2,000$ animal names) such that when the first three or four letters are identified, the computer automatically completes the word and enters it into the text space; therefore, the patients are not penalized points for spelling. Similarly, perseverative effects are controlled for such that repeated words are not rewarded. There are a total of 15 points possible for this section.

\section{Attention}

The attention section reflects components as described by Engle [53] such that the participants are asked to type in the names of 5 months prior to December in reverse order (e.g., December, November, October). This test maintains active engagement of working memory, attention, and concept organization. Like the other text entry subtests, the first three or four letters are automatically detected and entered. Spelling does not affect the total points for this section. There are a total of 5 points in this section.

\section{Orientation}

The participants are asked to recall the current year, current month, and current date. The auto-detection feature is also present in this section. There are a total of 3 points for this section.

\section{Processing speed}

The time or processing speed is used for comparison to control samples and statistical classification patients are not penalized for the total time. Time is measured for each subtest and for the total time of completion. Patients are advised that it is a timed test and are encouraged to complete it as quickly and accurately as possible. To prevent extraordinary amounts of time being used by non-interaction with the test, after 30 seconds of inactivation (e.g., no mouse or keyboard movement), the test will automatically progress to the next screen. Hence, inactivity will result in sections being missed thereby lowering the total score. 


\section{User interface}

The CST provides a user friendly interface and is easily manipulated with rudimentary computer skills. In our sample, the technician remained in the room with patient and or patient/caregiver for the entire test completion in order to passively monitor compliance, interactions, and record behavioral observations. Behavioral Rating Scales (BRS) were created for the technician to record observations and the severity of behavioral and psychiatric symptoms and functional ability. The BRS consist of a five point rating system $1=$ no problems or difficulty and $5=$ severe problems and difficulty. The ratings consist of orientation, motor functions, attention, and retention of task, comprehension, and awareness of task. In addition, the BRS recorded any attempts by the caregiver/or family member who were assisting the patient with the computer interface to improve the patient's score.

(ii) Mini Mental State Examination (MMSE) [59] (MiniMental, LLC): The MMSE is probably the most widely used test of cognitive function. It is extensively used as a screening tool in the diagnosis of dementia as well as to assess severity and change over time. The MMSE has a maximum score of 30 points. The test items are orientation to time and place (10 points), registration of 3 words (3), attention and calculation (5), recall of 3 words (3), language (8) and visual construction (1).

(iii) Executive Functions: The written test of executive functions is routinely administered to patients in the memory disorders clinic. This test assesses concept formation, attention, selfmonitoring and reasoning for abstract concepts, including proverbs and similarities [60]. It also presents three abstract concepts: How much does an elephant weigh? How many camels are in California? An abstract maze problem is given - a blank rectangle is presented with a problem: I have lost my keys on a football field, show me how you would search for them. Self monitoring, attention and self regulation are assessed by finger tapping tests [61]. The total possible score is 15 points.

(iv) Verbal Fluency: The test of verbal fluency contains three sections, each 1 minute in length. The participants are asked to recall as many animals + vegetables + fruits as possible within the allotted time. The cut-off for abnormal performance is $<38$ (total). (v) Mini-Cog: The Mini-Cog test is freely downloadable from http://www.hospitalmedicine.org /geriresource/toolbox/welcome.htm. It is a 3minute instrument used to screen for cognitive impairment in older adults. It utilizes a threeitem recall test for memory screening and a simply scored version of the clock drawing test serving as interference for the working memory task. The Mini-Cog was administered and scored utilizing the standard procedures in [62].

(vi) Geriatric Depression Scale (GDS): The Geriatric Depression Scale (GDS) is one of the most commonly used depression screening instruments in elderly populations. The scale is a 30 item, easily administer inventory that has been used widely to assess elderly populations in communities and institutions, including hospitals and nursing homes [63-66].

\section{Data analysis}

Discriminant Analysis was employed to determine the accuracy of the CST, MMSE, and Mini-Cog in the classification of cognitively impaired and control groups and in classification of the six groups in this study. Discriminant analysis builds a predictive model for group membership, which is composed of a set of discriminant functions based on linear combinations of the predictor variables that provide the superlative discrimination between the groups. We elected discriminant analysis based on its robustness despite modest violations to the assumptions of normality [67]. Procedures, however, typically violating multivariate normality (e.g., dichotomous variables) are not likely to affect conclusions based on discriminant analysis [68]. Reliability and validity analyses were conducted for the obtained scores on the CST comparing them to subtest scores on the MMSE, Mini-Cog, the paper version of the CST, and the written and administered versions of verbal fluency and executive functions. We compared the means between cognitively impaired and controls for demographic variables and total test scores not assuming equal variances. We then performed a testretest analysis for $38 \mathrm{CI}$ patients and 10 controls at $\sim$ six weeks. For this analysis we utilized a two-way random effects model with an absolute agreement definition and the Pearson product-moment correlation coefficient. Multivariate analysis of variance (MANOVA) was utilized to compare the diagnostic groups to determine significant differences for each diagnostic group compared to controls for the CST. The mean difference was compared using the Tukey adjustment with alpha $=0.05$. 


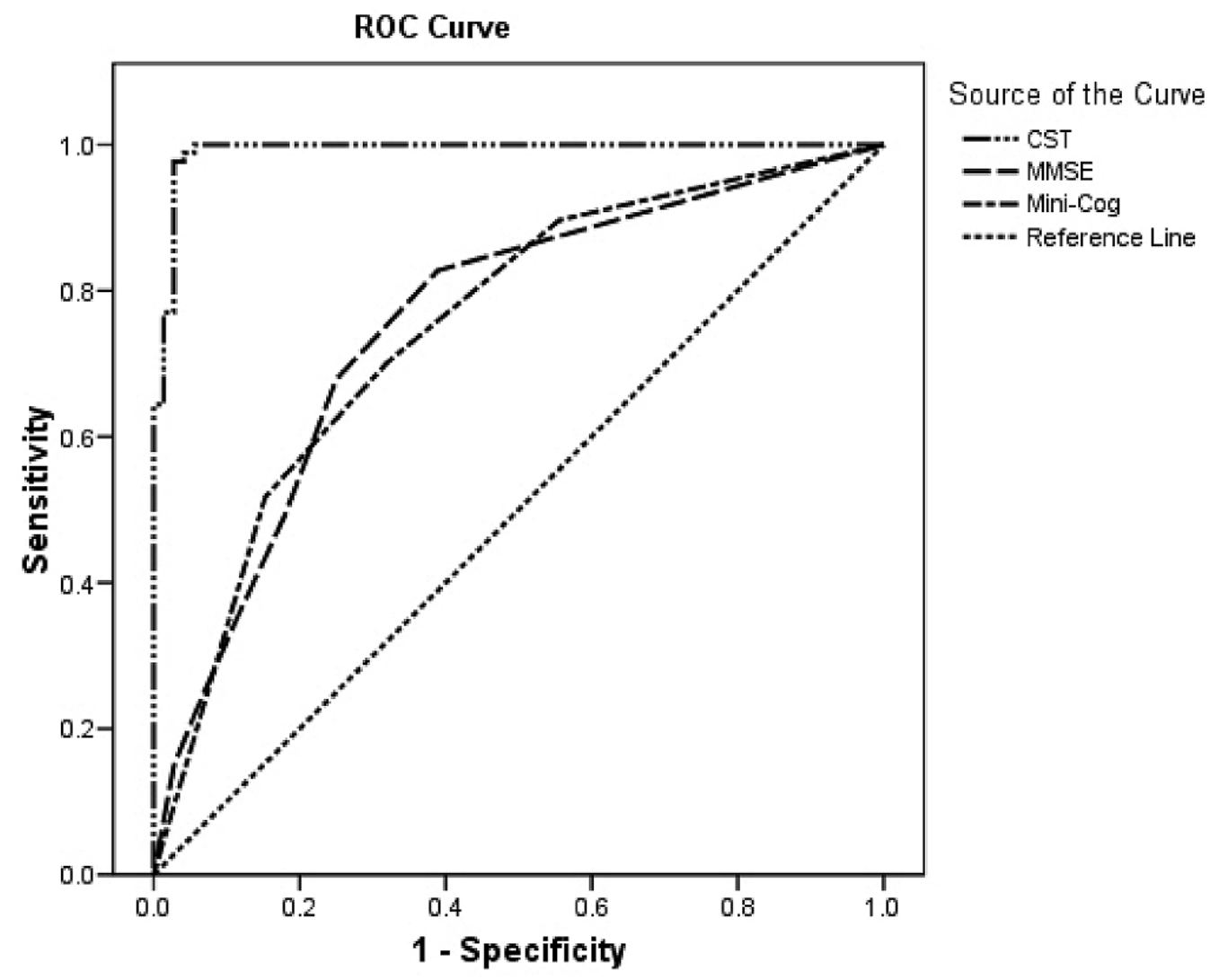

Fig. 1. ROC illustrating sensitivity and specificity of the CST, MMSE, and Mini-Cog for detection of cognitive impairment with MMSE cutoff at 24 .

\section{RESULTS}

\section{Accuracy, sensitivity, and specificity}

The discriminant analysis results show the CST correctly classified $91 \%$ of the six experimental groups listed in Table 1 , and $96 \%$ of the two groups (cognitively impaired and control). The MMSE correctly classified $54 \%$ of the six groups and $71 \%$ of the two groups. The Mini-Cog correctly classified $48 \%$ of the six groups and $69 \%$ of the two groups. The probabilities for group inclusion (normal/CI) from the discriminant analysis with the cutoff set at MMSE $=24$ were entered into a receiver-operating characteristic curve (ROC) analysis. The CST area under the curve (AUC) is $99 \%$, SE (0.006), p (0.000), with sensitivity of $99 \%$ and specificity of $95 \%$. The MMSE AUC is $82 \%$ SE (0.039), p (0.000) with sensitivity at $83 \%$ and specificity of $38 \%$. The Mini-Cog AUC is $89 \%$ SE (0.039), p (0.000) with sensitivity at $89 \%$ and specificity of $55 \%$. Figure 1 shows the ROC curves for each of the measures.

\section{Reliability and validity}

The total score for the CST is positively correlated with the total score on the MMSE, $r=0.56, p<0.000$. The CST orientation subtest shows significant correlations with the orientation to time $(r=0.79, p<0.000)$ and place $(r=0.66, p<0.000)$ of the MMSE. The working memory subtest for the CST is correlated with the recall test of the MMSE at significant levels ( $r=$ $0.61, p<0.000)$. The test of attention for the CST is correlated with the test of attention on the MMSE ( $r=$ $0.69, p<0.000)$. The verbal fluency subtest on the CST is correlated with test of verbal fluency $(r=0.53$, $p<0.000)$. Similarly the clock subtest is correlated with tests of executive functions $(r=0.35, p=0.003)$ and the intersecting pentagons subtest on MMSE $(r=$ $0.36, p=0.018$ ). We assessed reliability using a twoway random effects model with an internal consistency definition. The intra-class correlations (ICC) for the CST orientation subtest and MMSE orientation to both place and time are 0.72 for single measures and 0.88 for average measures $(p<0.00)$. The CST total 


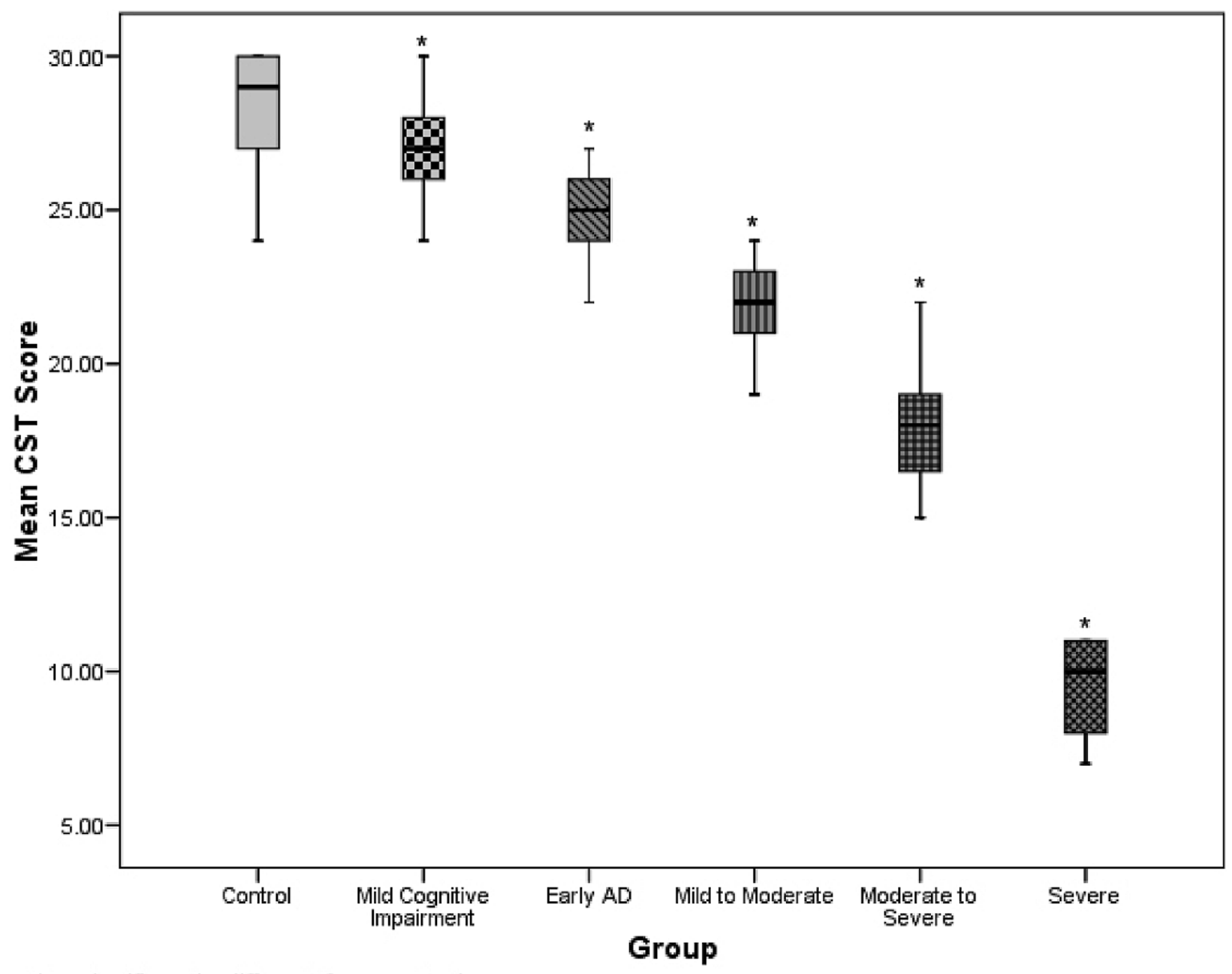

${ }^{*}=$ significantly different from control

Fig. 2. MANOVA results for mean CST scores for each of the diagnostic groups compared to controls.

score and scores on tests of executive functions (e.g., proverbs, finger tapping, similarities) show (ICC) of 0.43 for single measures and 0.61 for average measures $(p<0.00)$. The memory subtest on CST and recall on MMSE show an ICC of 0.61 for single measures and 0.76 for average measures $(p<0.00)$. The attention subtests on CST and MMSE show ICC of 0.27 for single measures and 0.43 for average measures ( $p=$ 0.04). The correlation between the CST and the paper version is $0.98,(p<0.01)$, similar results are shown for the internal consistency analysis between the CST and paper version (17) with an average measure of $0.98, \mathrm{~F}$ (155.13), $p<0.000$. The CST memory subtest shows a positive correlation to the total of the Mini-Cog 0.71 $(p<0.000)$, as does the total clock for CST $0.28,(p<$ $0.000)$. The test-retest for the total group of 48 at $\sim$ six weeks produces a Chronbach's alpha of 0.76 with $\mathrm{F}$ $(47)=4.17, p<0.00$.
Multivariate tests between diagnostic groups

The means for the CST for each diagnostic group are plotted in Fig. 2. On the y axis is the mean CST score and on the $\mathrm{x}$ axis are the diagnostic groups. The MANOVA results show the differences for each group compared to controls are significant. The MCI mean $26.96, \mathrm{SD}=1.63$, Mean difference $(\mathrm{MD})=1.43^{*}$, and standard error $(\mathrm{SE})=0.33$. The early $\mathrm{AD}$ group mean is $24.77, \mathrm{SD}=1.31, \mathrm{MD}=3.62^{*}, \mathrm{SE}=0.362$. The Mild to moderate group mean is $22.03, \mathrm{SD}=1.49, \mathrm{MD}=6.86^{*}$, $\mathrm{SE}=0.308$. The moderate to severe group mean is $17.83, \mathrm{SD}=1.83, \mathrm{MD}=10.56^{*}, \mathrm{SE}=0.349$. The severe group mean is $9.4, \mathrm{SD}=1.82, \mathrm{MD}=18.99 *, \mathrm{SE}=0.706$. The asterisk indicates significant at $<0.01$.

Table 2 shows the results for the univariate tests for the MANOVA procedure. In the table from left to right are the dependent variable, sum of squares, degrees of 
Table 2

Univariate tests for the MANOVA procedures. From left to right are demographic, self report and cognitive measures, the sum of squares and error, degrees of freedom, mean square, $\mathrm{F}$ for the test, significance, partial eta squared, and the observed power. Each of the dependent variables is significant when the diagnostic groups is a between subject factor. The partial eta (effect size) shows that the CST accounts for $89 \%$ of the variance between the groups in this study. The observed power indicates the sample size is adequate for the statistical procedures utilized

\begin{tabular}{|c|c|c|c|c|c|c|c|c|}
\hline Dependent variable & & Sum of squares & $\mathrm{df}$ & Mean square & $\mathrm{F}$ & Sig & Partial eta squared & Observed power (a) \\
\hline \multirow[t]{2}{*}{ CST } & Corthast & 4030.769 & 5 & 806.154 & 338.893 & 0.000 & 0.890 & 1.000 \\
\hline & Error & 497.166 & 209 & 2.379 & & & & \\
\hline \multirow[t]{2}{*}{ SRMP } & Corthast & 14.448 & 5 & 2.890 & 15.610 & 0.000 & 0.272 & 1.000 \\
\hline & Error & 38.687 & 209 & 0.185 & & & & \\
\hline \multirow[t]{2}{*}{ FM HX } & Corthast & 4.321 & 5 & 0.864 & 4.115 & 0.001 & 0.090 & 0.953 \\
\hline & Error & 43.893 & 209 & 0.210 & & & & \\
\hline \multirow[t]{2}{*}{ GENDER } & Corthast & 6.928 & 5 & 1.386 & 6.219 & 0.000 & 0.130 & 0.996 \\
\hline & Error & 46.561 & 209 & 0.223 & & & & \\
\hline \multirow[t]{2}{*}{ AGE } & Corthast & 1270.146 & 5 & 254.029 & 4.881 & 0.000 & 0.105 & 0.980 \\
\hline & Error & 10878.412 & 209 & 52.050 & & & & \\
\hline \multirow[t]{2}{*}{ CSTTIME } & Corthast & 220.380 & 5 & 44.076 & 3.969 & 0.002 & 0.087 & 0.945 \\
\hline & Error & 2320.705 & 209 & 11.104 & & & & \\
\hline \multirow[t]{2}{*}{ MINI-COG } & Corthast & 83.695 & 5 & 16.739 & 15.266 & 0.000 & 0.268 & 1.000 \\
\hline & Error & 229.161 & 209 & 1.096 & & & & \\
\hline \multirow[t]{2}{*}{ MMSE } & Corthast & 1886.741 & 5 & 377.348 & 37.573 & 0.000 & 0.480 & 1.000 \\
\hline & Error & 2044.580 & 209 & 9.783 & & & & \\
\hline
\end{tabular}

freedom, mean square, F value, significance level, partial eta squared (the proportion of the effect + error variance that is attributable to the effect), and the observed power (or adequacy of the sample size for the statistical procedure). The mean time for completion of the CST in minutes and seconds is $\leqslant 6.10$ for controls, 7.5 for MCI, 8.11 for early AD, 8.57 for mild to moderate, and $\geqslant 9.00$ for both moderate to severe and severe. Clinical observations suggest that if the patient takes longer than 13 minutes to complete the CST, the score will not improve. Similarly, the more severe groups may finish the CST in as little as 3 minutes due to the inability to complete the items.

The results of the t-tests between CI and controls for all behavioral ratings (BRS) show the CI group exhibits more difficulties in orientation $\mathrm{t}$ (5.48), $p<0.000$, motor functions t (3.65), $p<0.000$, attention $\mathrm{t}$ (6.02), $p<$ 0.000 , task comprehension $\mathrm{t}$ (3.97), $p<0.000$, task retention $\mathrm{t}(6.23), p<0.000$. The $\mathrm{CI}$ group had significantly more caregiver assisted administration than controls t (6.78), $p<0.000$. Of interest the CI group reported more computer literacy than controls with $\mathrm{t}$ (5.76), $p<0.000$ ) (possibly associated with anosoagnosia). The degree of difficulty with self administration increases relative to the stage of the disease. Thus far, the data indicate that the caregiver assisted administration did not affect the accuracy of the discriminant classification.

\section{DISCUSSION}

The CST provides an alternative to traditional paper based methods for assessing neurobehavioral and cog- nitive functions. The individual may complete the CST alone or receive assistance from a caregiver or other non-professional acting only to facilitate the computer interface. The current data indicate that the CST is a valid and sensitive instrument for evaluating functional deficits in both global and specific cognitive domains. The total CST score, processing speed (time to complete the CST), self-report of memory problems, age, family history of $\mathrm{AD}$, and gender offer a reliable and accurate prediction model for classifying and discriminating between normal, MCI, and various stages within AD for the population in our study. Recent data suggests that $21 \%$ of a multiethnic group of normal elderly subjects progressed to MCI at a rate of $5 \%$ per year. For those individuals presenting initially with MCI, $22 \%$ were subsequently diagnosed with $\mathrm{AD}$ at a rate of $5 \%$ per year [69]. $47 \%$ of the cohort remained unchanged and a rather large number $(31 \%)$ reverted to normal. Individuals with MCI that had impairments in memory and at least one other cognitive domain were shown to be highly associated with greatest risk for conversion to $\mathrm{AD}$ and these patients were less likely to revert to normal at follow-up [69]. In addition, research has shown that AD patients may show cognitive deficits many years prior to the diagnosis of dementia [70,71].

The CST shows a high rate of successfully classifying global cognitive impairment from normal cognitive functioning and does so with significant accuracy, sensitivity, and specificity with the consideration that increased sample size does increase the additive property of screening tests [48]. The current findings are important for populations exhibiting early symptoms of 
MCI as well as those individuals that have a family history of AD. Early computerized cognitive monitoring may prove important for both populations exhibiting early functional symptoms as well as those individuals that have a family history of AD. In addition, as the population ages many individuals become increasingly concerned about their own cognitive health (i.e., the worried well) [72].

The CST provides an easily interpreted and administered method of obtaining a baseline of cognitive functioning. One of the primary objectives for the CST is to increase the likelihood of detecting the earliest declines in cognitive functioning in order to decrease the number of individuals that go undiagnosed in the primary care setting. However, with the development of any screening test, expressed consideration needs to be given to reducing the likelihood of a misdiagnosis or false positive. The CST does not provide any diagnostic information to the patient in the results section. Painstaking effort was put into the wording and presentation of deficits such that the likelihood of an interpretation of dementia from the results is minimized. The benefits of correct detection of deficits for the patient include the implementation of more extensive assessment and testing procedures to accurately diagnose the syndrome and initiation of medications that have been shown to produce positive benefits [4]. The harm due to false positive results involves not only the cost of further testing but also the emotional effects on the patient. These issues are discussed in more detail in a recent review [48].

If the data obtained in this early study continues to demonstrate, as larger samples become available, a distinct pattern of variable cognitive changes in MCI and stages of AD an emerging concept of a domain specific cognitive patterns (DSCP) may continue to develop. This concept may offer a novel and important direction for further research. It will be possible to construct large data sets for standardizing DSCP in order to identify deficits and classify individual patients more quickly and accurately.

The CST, in the current population, is sensitive to differences between normal, MCI, and stages within AD by assessing functionality in six cognitive domains (memory, verbal fluency, orientation, visuospatial organization, executive function, and attention). The MANOVA results show there are significant deficits for the CI group as compared to controls. The effect size for the CST accounts for $89 \%$ of the variance between all diagnostic groups. Additionally, the variables included in the discriminant function appear to provide an accurate predictive model. However, future research will include additional cognitive modules and intensive analysis of the functional relationships between cognitive component-processes.

Several additions may strengthen the current study. It is inherently true that any screening instrument will perform more efficiently in predefined groups as opposed to consecutive or unknown populations. Further analysis of concurrent validity with other widely used cognitive screening instruments (MoCA, Dementia Rating Scale, WAIS memory scale) is desirable. Recent research suggests that practice effects are evident for some of the tasks in the CogState battery [73]. We would also like to obtain large samples of ethnic and culturally diverse populations for further study and standardization. The population in this study is from one local center with mostly Caucasian individuals with a high degree of the patients being welleducated; therefore, larger samples are needed. These limitations will continue to be addressed as our research continues. The CST utilizes variations of substantiated neurocognitive assessment procedures and further additions are planned. Additionally, upon the completion of more clinical trials and independent validation the discriminant functions will be available via internet access for physicians to determine the probability of inclusion in specific diagnostic groups based on the patient's individual domain specific cognitive profile. The results of the discriminant analysis will provide the specific probability of inclusion into specific diagnostic groups. All patients in this study are followed in the memory disorders clinic and we will continue to obtain longitudinal data. This system of testing will continue to develop and we will be incorporating other clinical populations (i.e., non-amnestic and non-AD dementia types) in future studies.

\section{ACKNOWLEDGMENTS}

The authors would like to express sincere gratitude to Dr. Richard Gibson, A.D. Baxter and Libby Hall for their contributions and conscientious effort in the memory disorders clinic. The authors express sincere gratitude to Charles Licata and Mateja de Leonni Stanonik for their dedicated work in the development of the paper self test. The authors also would like to thank the patients, family members and volunteers that participated in this study.

Authors' disclosures available online (http://www.jalz.com/disclosures/view.php?id=232). 


\section{REFERENCES}

[1] Flaks MK, Yassuda MS, Regina AC, Cid CG, Camargo CH, Gattaz WF, Forlenza OV (2006) The Short Cognitive Performance Test (SKT): a preliminary study of its psychometric properties in Brazil. Int Psychogeriatr 18, 121-133.

[2] Kalbe E, Salmon E, Perani D, Holthoff V, Sorbi S, Elsner A, Weisenbach S, Brand M, Lenz O, Kessler J, Luedecke S, Ortelli P, Herholz K (2005) Anosognosia in very mild Alzheimer's disease but not in mild cognitive impairment. Dement Geriatr Cogn Disord 19, 349-356.

[3] Cullen B, O'Neill B, Evans JJ, Coen RF, Lawlor BA (2007) A review of screening tests for cognitive impairment. J Neurol Neurosurg Psychiatry 78, 790-799.

[4] Tinklenberg JR, Kraemer HC, Yaffe K, Ross L, Sheikh J, Ashford JW, Yesavage JA, Taylor JL (2007) Donepezil treatment and Alzheimer disease: can the results of randomized clinical trials be applied to Alzheimer disease patients in clinical practice? Am J Geriatr Psychiatry 15, 953-960.

[5] Petersen RC, Thomas RG, Grundman M, Bennett D, Doody R, Ferris S, Galasko D, Jin S, Kaye J, Levey A, Pfeiffer E, Sano M, van Dyck CH, Thal LJ (2005) Vitamin E and donepezil for the treatment of mild cognitive impairment. $N$ Engl J Med 352, 2379-2388.

[6] Knopman DS (2006) Current treatment of mild cognitive impairment and Alzheimer's disease. Curr Neurol Neurosci Rep 6, 365-371.

[7] Evans R ed. (1999) Diagnostic Testing in Neurology, W.B. Saunders, Philadelphia.

[8] Ashford JW, Borson S (2008) Primary care screening for dementia and mild cognitive impairment. JAMA 299, 1132-1133; author reply 1133-1134.

[9] Ashford JW, Borson S, O'Hara R, Dash P, Frank L, Robert P, Shankle WR, Tierney MC, Brodaty H, Schmitt FA, Kraemer HC, Buschke H, Fillit H (2007) Should older adults be screened for dementia? It is important to screen for evidence of dementia! Alzheimers Dement 3, 75-80.

[10] Petersen RC, Bennett D (2005) Mild cognitive impairment: is it Alzheimer's disease or not? J Alzheimers Dis 7, 241-245; discussion 255-262.

[11] Petersen RC, Morris JC (2005) Mild cognitive impairment as a clinical entity and treatment target. Arch Neurol 62, 11601163; discussion 1167.

[12] Petersen RC, Smith GE, Waring SC, Ivnik RJ, Tangalos EG, Kokmen E (1999) Mild cognitive impairment: clinical characterization and outcome. Arch Neurol 56, 303-308.

[13] Flicker C, Ferris SH, Reisberg B (1991) Mild cognitive impairment in the elderly: predictors of dementia. Neurology 41, 1006-1009.

[14] Morris JC, Cummings J (2005) Mild cognitive impairment (MCI) represents early-stage Alzheimer's disease. $J$ Alzheimers Dis 7, 235-239; discussion 255-262.

[15] Yesavage JA, O'Hara R, Kraemer H, Noda A, Taylor JL, Ferris S, Gely-Nargeot MC, Rosen A, Friedman L, Sheikh J, Derouesne C (2002) Modeling the prevalence and incidence of Alzheimer's disease and mild cognitive impairment. J Psychiatr Res 36, 281-286.

[16] Hofman M, Seifritz E, Krauchi K, Hock C, Hampel H, Neugebauer A, Muller-Spahn F (2000) Alzheimer's disease, depression and normal ageing: merit of simple psychomotor and visuospatial tasks. Int J Geriatr Psychiatry 15, 31-39.

[17] Kinjo H (2007) Improving sensitivity of the recognition task in the Alzheimer's Disease Assessment Scale. Psychol Rep 100, 420-426.
[18] Kilada S, Gamaldo A, Grant EA, Moghekar A, Morris JC, O’Brien RJ (2005) Brief screening tests for the diagnosis of dementia: comparison with the mini-mental state exam. Alzheimer Dis Assoc Disord 19, 8-16.

[19] Knopman DS (1998) Current pharmacotherapies for Alzheimer's disease. Geriatrics 53 Suppl 1, S31-34.

[20] Trenkle DL, Shankle WR, Azen SP (2007) Detecting cognitive impairment in primary care: performance assessment of three screening instruments. J Alzheimers Dis 11, 323-335.

[21] Brown J, Pengas G, Dawson K, Brown LA, Clatworthy P (2009) Self administered cognitive screening test (TYM) for detection of Alzheimer's disease: cross sectional study. $B M J$ 338, b2030.

[22] De Jager CA, Hogervorst E, Combrinck M, Budge MM (2003) Sensitivity and specificity of neuropsychological tests for mild cognitive impairment, vascular cognitive impairment and Alzheimer's disease. Psychol Med 33, 1039-1050.

[23] de Jager CA, Schrijnemaekers AC, Honey TE, Budge MM (2009) Detection of MCI in the clinic: evaluation of the sensitivity and specificity of a computerised test battery, the Hopkins Verbal Learning Test and the MMSE. Age Ageing 38, 455-460.

[24] de Leonni Stanonik M, Licata CA, Walton NC, Lounsbury JW, Hutson RK, Dougherty JH, Jr. (2005) The Self Test: a screening tool for dementia requiring minimal supervision. Int Psychogeriatr 17, 669-678.

[25] Saxton J, Morrow L, Eschman A, Archer G, Luther J, Zuccolotto A (2009) Computer assessment of mild cognitive impairment. Postgrad Med 121, 177-185.

[26] Saxton J, Snitz BE, Lopez OL, Ives DG, Dunn LO, Fitzpatrick A, Carlson MC, Dekosky ST (2009) Functional and cognitive criteria produce different rates of mild cognitive impairment and conversion to dementia. J Neurol Neurosurg Psychiatry 80, 737-743.

[27] Kalman J, Magloczky E, Janka Z (1995) Disturbed visuospatial orientation in the early stage of Alzheimer's dementia. Arch Gerontol Geriatr 21, 27-34.

[28] Wright M, Geffen G, Geffen L (1997) Comparative effects of ageing and dementia of the Alzheimer type on orientation of visual attention. Dement Geriatr Cogn Disord 8, 366-375.

[29] Borson S, Brush M, Gil E, Scanlan J, Vitaliano P, Chen J, Cashman J, Sta Maria MM, Barnhart R, Roques J (1999) The Clock Drawing Test: utility for dementia detection in multiethnic elders. J Gerontol A Biol Sci Med Sci 54, M534540.

[30] Heinik J, Solomesh I, Shein V, Becker D (2002) Clock drawing test in mild and moderate dementia of the Alzheimer's type: a comparative and correlation study. Int J Geriatr Psychiatry 17, 480-485.

[31] Schramm U, Berger G, Muller R, Kratzsch T, Peters J, Frolich L (2002) Psychometric properties of Clock Drawing Test and MMSE or Short Performance Test (SKT) in dementia screening in a memory clinic population. Int J Geriatr Psychiatry 17, 254-260.

[32] Cummings JL (2004) The one-minute mental status examination. Neurology 62, 534-535.

[33] Murphy KJ, Rich JB, Troyer AK (2006) Verbal fluency patterns in amnestic mild cognitive impairment are characteristic of Alzheimer's type dementia. J Int Neuropsychol Soc 12, 570-574.

[34] Backman L (2008) Memory and cognition in preclinical dementia: what we know and what we do not know. Can J Psychiatry 53, 354-360. 
[35] Backman L, Jones S, Berger AK, Laukka EJ, Small BJ (2005) Cognitive impairment in preclinical Alzheimer's disease: a meta-analysis. Neuropsychology 19, 520-531.

[36] Barnes LL, Schneider JA, Boyle PA, Bienias JL, Bennett DA (2006) Memory complaints are related to Alzheimer disease pathology in older persons. Neurology 67, 1581-1585.

[37] Sambataro F, Murty VP, Callicott JH, Tan HY, Das S, Weinberger DR, Mattay VS (2008) Age-related alterations in default mode network: Impact on working memory performance. Neurobiol Aging, in press.

[38] Pereira FS, Yassuda MS, Oliveira AM, Forlenza OV (2008) Executive dysfunction correlates with impaired functional status in older adults with varying degrees of cognitive impairment. Int Psychogeriatr, 1-12.

[39] Traykov L, Raoux N, Latour F, Gallo L, Hanon O, Baudic S, Bayle C, Wenisch E, Remy P, Rigaud AS (2007) Executive functions deficit in mild cognitive impairment. Cogn Behav Neurol 20, 219-224.

[40] Thomann PA, Toro P, Dos Santos V, Essig M, Schroder J (2008) Clock drawing performance and brain morphology in mild cognitive impairment and Alzheimer's disease. Brain Cogn 67, 88-93.

[41] Zhou Y, Dougherty JH, Jr., Hubner KF, Bai B, Cannon RL, Hutson RK (2008) Abnormal connectivity in the posterior cingulate and hippocampus in early Alzheimer's disease and mild cognitive impairment. Alzheimers Dement 4, 265-270.

[42] Backman L, Jones S, Berger AK, Laukka EJ, Small BJ (2004) Multiple cognitive deficits during the transition to Alzheimer's disease. J Intern Med 256, 195-204.

[43] American Psychiatric Association (2000) Diagnostic and statistical manual of mental disorders (4th ed., text revision). Washington, DC

[44] (1998) Guidelines for the evaluation of dementia and agerelated cognitive decline. American Psychological Association Presidential Task Force. Am Psychol 53, 1298-1303.

[45] Petersen RC (2004) Mild cognitive impairment as a diagnostic entity. J Intern Med 256, 183-194.

[46] Nasreddine ZS, Phillips NA, Bedirian V, Charbonneau S, Whitehead V, Collin I, Cummings JL, Chertkow H (2005) The Montreal Cognitive Assessment, MoCA: a brief screening tool for mild cognitive impairment. J Am Geriatr Soc 53, 695-699.

[47] Olson RA, Chhanabhai T, McKenzie M (2008) Feasibility study of the Montreal Cognitive Assessment (MoCA) in patients with brain metastases. Support Care Cancer 16, 12731278.

[48] Ashford AE (2008) Screening for memory disorders, dementia and Alzheimer's disease. Aging Health 4, 399-432.

[49] Cahn DA, Salmon DP, Monsch AU, Butters N, Wiederholt WC, Corey-Bloom J, Barrett-Connor E (1996) Screening for dementia of the alzheimer type in the community: the utility of the Clock Drawing Test. Arch Clin Neuropsychol 11, 529-539.

[50] Lessig MC, Scanlan JM, Nazemi H, Borson S (2008) Time that tells: critical clock-drawing errors for dementia screening. Int Psychogeriatr 20, 459-470.

[51] Raz N, Rodrigue KM (2006) Differential aging of the brain: patterns, cognitive correlates and modifiers. Neurosci Biobehav Rev 30, 730-748.

[52] Cosentino S, Jefferson A, Chute DL, Kaplan E, Libon DJ (2004) Clock drawing errors in dementia: neuropsychological and neuroanatomical considerations. Cogn Behav Neurol 17, 74-84.

[53] Engle RW, Tuholski SW, Laughlin JE, Conway AR (1999) Working memory, short-term memory, and general fluid intel- ligence: a latent-variable approach. J Exp Psychol Gen 128, 309-331.

[54] Baddeley A, Hitch GJL (1974) Working Memory. in The psychology of learning and motivation: advances in research and theory, Academic Press, New York.

[55] Baddeley A, Cocchini G, Della Sala S, Logie RH, Spinnler H (1999) Working memory and vigilance: evidence from normal aging and Alzheimer's disease. Brain Cogn 41, 87-108.

[56] Baddeley AD, Bressi S, Della Sala S, Logie R, Spinnler H (1991) The decline of working memory in Alzheimer's disease. A longitudinal study. Brain 114 (Pt 6), 2521-2542.

[57] Cannon R, Congedo, M, Lubar, J., Hutchens, T. (2009) Differentiating at network of executive attention: LORETA Neurofeedback in anterior cingulate and dorsolateral prefrontal cortices. Int J Neurosci 119, 404-441.

[58] Cannon R, Lubar J, Congedo M, Thornton K, Towler K, Hutchens $\mathrm{T}$ (2007) The effects of neurofeedback training in the cognitive division of the anterior cingulate gyrus. Int $J$ Neurosci 117, 337-357.

[59] Folstein MF, Folstein SE, McHugh PR (1975) "Mini-mental state". A practical method for grading the cognitive state of patients for the clinician. J Psychiatr Res 12, 189-198.

[60] Lafleche GaMSA (1995) Executive Function Deficits in Mild Alzheimer's Disease. Neuropsychology 9, 313-320.

[61] Prigatano GP, Johnson SC, Gale SD (2004) Neuroimaging correlates of the Halstead Finger Tapping Test several years post-traumatic brain injury. Brain Inj 18, 661-669.

[62] Borson S, Scanlan J, Brush M, Vitaliano P, Dokmak A (2000) The mini-cog: a cognitive 'vital signs' measure for dementia screening in multi-lingual elderly. Int J Geriatr Psychiatry $\mathbf{1 5}$, 1021-1027.

[63] Yesavage J (1993) Differential diagnosis between depression and dementia. Am J Med 94, 23S-28S.

[64] Yesavage JA (1991) Geriatric depression scale: consistency of depressive symptoms over time. Percept Mot Skills 73, 1032.

[65] Yesavage JA (1988) Geriatric Depression Scale. Psychopharmacol Bull 24, 709-711.

[66] Yesavage JA, Brink TL, Rose TL, Lum O, Huang V, Adey M, Leirer VO (1982) Development and validation of a geriatric depression screening scale: a preliminary report. J Psychiatr Res 17, 37-49.

[67] Lachenbruch PA (1975) Discriminant Analysis. Biometrics 35, 69-85.

[68] Klecka WR (1980) Discriminant Analysis, Sage Publications, Beverly Hills.

[69] Manly JJ, Tang MX, Schupf N, Stern Y, Vonsattel JP, Mayeux R (2008) Frequency and course of mild cognitive impairment in a multiethnic community. Ann Neurol 63, 494-506.

[70] Kemper S, Marquis J, Thompson M (2001) Longitudinal change in language production: effects of aging and dementia on grammatical complexity and propositional content. Psychol Aging 16, 600-614.

[71] La Rue A, Jarvik LF (1987) Cognitive function and prediction of dementia in old age. Int J Aging Hum Dev 25, 79-89.

[72] Ahmed S, Mitchell J, Arnold R, Dawson K, Nestor PJ, Hodges JR (2008) Memory complaints in mild cognitive impairment, worried well, and semantic dementia patients. Alzheimer Dis Assoc Disord 22, 227-235.

[73] Falleti MG, Maruff P, Collie A, Darby DG (2006) Practice effects associated with the repeated assessment of cognitive function using the CogState battery at 10-minute, one week and one month test-retest intervals. J Clin Exp Neuropsychol 28, 1095-1112. 